\title{
FATORES QUE INFLUENCIAM O VIGOR E OS MÉTODOS DE AVALIAÇÃO DO VIGOR DE SEMENTES: UMA REVISÃO
}

\author{
Manoel Victor Borges Pedrosa ${ }^{1}$ \\ Melissa Alvarenga de Oliveira ${ }^{2}$ \\ Alice de Freitas Braga ${ }^{3}$ \\ Nathália Bragança Aparecida Fávaris ${ }^{4}$ \\ Lucimara Ribeiro Venial ${ }^{5}$ \\ Allan Rocha de Freitas ${ }^{6}$ \\ José Carlos Lopes ${ }^{7}$ \\ Rodrigo Sobreira Alexandre ${ }^{8}$
}

Resumo: O vigor de sementes pode ser entendido como a soma de características que possibilitam às sementes a capacidade de germinar e de emergir plântulas normais de forma rápida, independente das condições ambientais presentes no local. Objetivou-se realizar um levantamento de trabalhos referente aos principais fatores que podem afetar o vigor e os testes realizados para a avalição do vigor das sementes. $A$ produção de sementes se caracteriza como um processo complexo, sendo necessário um controle de todas as condições e fatores que podem interferir no seu desenvolvimento. Sementes vigorosas originam plântulas vigorosas, o que resultam em elevada porcentagem de plantas no estande final da cultura. Os métodos diretos e indiretos para a avaliação do vigor das sementes mostram-se eficientes. Todavia, o método mais adequado é variável para cada espécie.

Palavras-chave: Germinação; Crescimento inicial; Plântulas; Teste.

\footnotetext{
1 Biólogo, Mestrando em Produção Vegetal, Universidade Federal do Espírito Santo - UFES, Brasil. E-mail: mvborgespedrosa@gmail.com.

2 Graduanda de Engenharia Agronômica, Universidade Federal do Espirito Santo - UFES, Brasil. E-mail: melissalvarengao@gmail.com.

3 Graduanda de Engenharia Agronômica, Universidade Federal do Espirito Santo - UFES, Brasil. E-mail: alicefreitasbraga@hotmail.com.

${ }^{4}$ Graduanda de Engenharia Agronômica, Universidade Federal do Espirito Santo - UFES, Brasil. E-mail: nathbraganca@hotmail.com.

${ }^{5}$ Engenheira Agrônoma, Mestranda em Produção Vegetal, Universidade Federal do Espírito Santo - UFES, Brasil. E-mail: luci_venial@hotmail.com.

${ }^{6}$ Engenheiro Agrônomo, Dr., em Produção Vegetal, Universidade Federal do Espírito Santo - UFES, Brasil. Email: allanrochaf@gmail.com.

${ }^{7}$ Engenheiro Agrônomo, Dr., Professor do Departamento de Produção Vegetal, Centro de Ciências Agrárias, Universidade Federal do Espírito Santo - UFES, Brasil. E-mail: jcufes@bol.com.br.

${ }^{8}$ Engenheiro Agrônomo, Dr., Professor do Departamento de Ciências Florestais e da Madeira, Centro de Ciências Agrárias, Universidade Federal do Espírito Santo - UFES, Brasil. E-mail: rodrigosobreiraalexandre@gmail.com.
} 